\section{Noticias y comentarios}

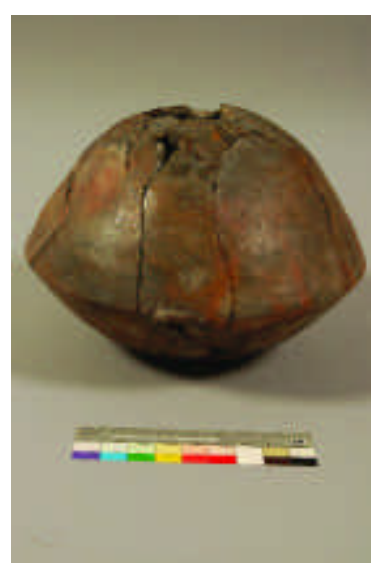

Vasija argárica antes de la restauración

\title{
Cerámicas de Los Millares y El Argar se someten a un proceso de conservación-restauración
}

El taller de materiales arqueológicos del IAPH ha llevado a cabo la restauración de una serie de piezas procedentes del Museo de Almería. Esta intervención se enmarca dentro del nuevo proyecto museológico que busca destacar en la exposición permanente del museo la importancia que han tenido para la prehistoria almeriense las culturas de Los Millares y El Argar.

Dentro del conjunto de piezas intervenidas, entre las que hay objetos de metal (armas y objetos de adorno) y hueso (punzones e idolillos), destaca especialmente la cerámica, no sólo en número de piezas, sino también, por constituir un elemento de primer orden en la cultura material tanto de Los Millares (III milenio a.c.) como de El Argar (inicios del II milenio-1.300 a.c.).

En ambos casos podemos distinguir entre cerámica destinada a uso doméstico, en la que existe una mayor diversidad tipológica (cuencos, platos, vasos...) en piezas destinadas fundamentalmente a la preparación de alimentos y al almacenamiento, y la que tiene carácter funerario que se encuentra formando parte del ajuar en los enterramientos. Dentro de esta última presentan un gran interés las cerámicas simbólicas de la cultura de Los Millares con superficies pulidas y bruñidas y decoradas con motivos incisos de soles y ramiformes.

La cerámica funeraria de la cultura de El Argar también presenta diferencias desde el punto de vista tecnológico con los recipientes de uso común por su temperatura de cocción más baja, la arcilla más depurada y la superficie muy bruñida de brillo metálico. Se trata fundamentalmente de vasijas carenadas, ovoides y cuencos.

El estado de conservación de las piezas seleccionadas para su conservación-restauración en el IAPH era muy desigual. La mayoría presentaban intervenciones anteriores en las que se habian seguido criterios muy dispares. Estas consisten en la unión de fragmentos con distintos tipos de adhesivos, la reconstrucción de las lagunas con escayola y el entonado final. En muchos casos estas intervenciones han acentuado el deterioro al crear fuertes tensiones en la pasta cerámica, haberse procedido al lijado de bordes de fractura o presentar aproximaciones de color poco acertadas que impedian la correcta lectura de la pieza, no sólo por el resultado cromático, sino porque cubrian en parte el original rebasando las lagunas.
El tratamiento realizado se ha basado fundamentalmente en dos premisas: la conservación de las piezas y su correcta lectura, que han determinado la elección del tratamiento a aplicar en cada caso. En líneas generales, y tenier do en cuenta el estado que presentaban la mayoría de las cerámicas, éste ha consistido en limpieza mecánica y química, rebaje de las reintegraciones volumétricas existentes y reintegración cromática. La limpieza ha constituido una fase fundamental en el caso de las cerámicas que presentaban depósitos terrosos desiguat mente repartidos por la superficie, goterones de adhesivo o restos de etiquetas.

En los casos en los que la intervención anterior se había limitado a la unión de fragmentos se ha procedido a reintegrar únicamente aquellas pérdidas o lagunas que se consideraban esen ciales para aportar estabilidad estructural a la pieza. Las reintegraciones volumétricas existen tes, cuando se han mantenido, se han rebajado con la intención de potenciar el original a través de una diferenciación clara de las lagunas que, de esta forma, quedan mejor delimitadas. A esto último contribuye la reintegración cromática mediante una tinta plana con un tono ligeramente inferior que se aproxime en lo posible a las distintas tonalidades que son características de esta cerámica y que vienen dadas, no sólo por el tipo de cocción oxidante o reductora sino, también, por la propia materia prima, los usos a los que fue sometida...

En casos puntuales ha sido necesario llevar a cabo desalaciones y fijaciones ya que, por lo general, no se apreciaban problemas de sales y la superficie cerámica se encontraba en buen estado.

Entre los diversos restos materiales procedentes de los yacimientos de la prehistoria almeriense la cerámica constituye un documento material que aporta una valiosa información acerca de los procesos tecnológicos empleados en su fabricación pero también acerca de los usos a los que fue destinada y, en términos generales, de todo el horizonte cultural al que pertenece.

Constanza Rodriguez Segovia

Centro de Intervención del IAPH 